\title{
Giant Prostate
}

\section{Elton Cekaj}

Tirana, Albania

\section{Clinical History}

The patient presented in emergency with urinary retention and mental confusion state. With abdominal ultrasound was impossible to differentiate the anechoic cystic masses and the prostate so the head and abdominal computed tomography were performed. Contrast media was not administered cause of high level of serum creatinine $(9 \mathrm{mg} /$ dl)

\section{Imaging Findings}

In abdominal computed tomography (CT) was found hydronephrosis on both kidneys, with dilatated and tortuous ureters, a large stone in left renal pelvis, a lot of small stones in distal part of left ureter, a lot of small stones in urinary bladder (figures 1, 2, 3, 4). But the surprising CT finding was the prostate size. It resulted with 106.8 x 101.9 x 120.1 $\mathrm{cm}$ in its three dimensions with a total volume of $684 \mathrm{cc}$ or an equivalent weight of 718.2 grams. In the meantime the residual urine volume resulted in nearly 1.71 liters (figures $5,6,7)$. The residual urine was removed via transabdominal punction. Unfortunately the patient died four days after cause of cerebral coma.

\section{Discussion}

The prostate gland is a flattened, conical structure orientated in the coronal plane. Its apex points downward and is located just above the deep fascia of the urogenital diaphragm. Its anterior surface is directed toward the symphysis, from which it is separated by adipose tissue and periprostatic veins. The length of the normal prostate is 2.5$3.0 \mathrm{~cm}$, the transverse diameter at the base is $4-4.5 \mathrm{~cm}$ and the thickness is $2-2.5 \mathrm{~cm}$. The dimensions often increase with age, mainly after the fourties and the normal weight of 20-25 g may be surpassed several times [1]. Benign prostatic hypertrophy (BPH) is a benign nodular enlargement of the prostate gland. Histologically, changes of BPH may be predominantly glandular, less commonly interstitial [1], or both. The effects of BPH on the urethra, bladder, or kidneys are related to the size and predominant location of the mass [1][2] Nodular prostatic enlargement is the most common and can result in constriction of the urethra and subsequent bladder obstruction due to affliction of the central gland. Transrectal ultrasound is the examination of choice to evaluate $\mathrm{BPH}$, but very large prostate needs to be evaluated with CT or MRI. On CT, the enlarged gland includes nodules that can have both high-and low-attenuation regions in addition to variable enhancement. Coarse calcifications are common in BPH. On CT, as a general rule, the prostate is not considered to be enlarged if a section obtained $1 \mathrm{~cm}$ above the symphysis does not include the prostate. Unequivocal enlargement of the prostate is diagnosed if the prostate is seen on sections $2-3 \mathrm{~cm}$ or more above the symphysis. On these sections, the prostate, if enlarged, is usually surrounded by the bladder. As in ultrasound the prostate volume is measured with this formula: $\pi / 6 \times$ high $\mathrm{x}$ width $\mathrm{x}$ length and to calculate the weight this must be multiple by 1.05 . On MRI, the appearance of BPH varies depending on the imaging sequence used (T1- or T2-weighted) and the histological type (glandular, stromal, or mixed). BPH is indistinguishable from prostate carcinoma on CT, and despite the aforementioned features, MRI is also unable to distinguish benign from malignant prostate [3][4][5][6][7]. In some people, the prostate enlarges massively; eventually weighing more than 500 grams and this is defined as giant prostatic hyperplasia. Prostate more than 500 grams was found in very few cases all around the world [8][9] and this is a very rare new one.

\section{Differential Diagnosis List}

- Pelvic masses

- Prostate cancer

- Diverticulum of urinary bladder

\section{Final Diagnosis}

Giant prostate

\section{References}

[1] McNeal JE (1983) The prostate gland. Morphology and pathobiology. Monogr Urol 4:5-13

[2] Berry SJ, Coffey DS, Walsh PC, Ewing LL (1984) The development of human benign prostatic hyperplasia with age. J Urol 132:474-9

[3] Maio A, Rifkin MD (1995) Magnetic resonance imaging of prostate cancer: Update. Top Magn Reson Imaging 7:54-68

[4] Dennis MA, Donohue RE (1985) Computed tomography of prostatic abscess. J Comput Assist Tomogr 9:201-202

[5] Ling D, Lee JK, Heiken JP, et al (1986) Prostatic carcinoma and benign prostatic hyperplasia: Inability of MR imaging to distinguish between the two diseases. Radiology 158:103-107

[6] Schiebler ML, Tomaszewski JE, Bezzi M, et al (1989) Prostatic carcinoma and benign prostatic hyperplasia: Correlation of high-resolution MR and histopathologic findings. Radiology 172:131-137

[7] Shivadeo S Bapat, Satyajeet S Purnapatre, Ketan V Pai, Pushkaraj Yadav, Abhijit Padhye, YG Bodhe (2006) Does estimation of prostate volume by abdominal ultrasonography vary with bladder volume: A prospective study with transrectal ultrasonography as a reference. Indian journal of urology 22.4:322-325

[8] E Akpo, M Akpo (2010) Giant Benign Prostatic Hyperplasia In A Nigerian: Report Of A Case. The

\section{Volume 5 Issue 7, July 2016




\section{International Journal of Science and Research (IJSR) \\ ISSN (Online): 2319-7064 \\ Index Copernicus Value (2013): 6.14 | Impact Factor (2015): 6.391}

Internet Journal of Urology 8:1

[9] Joseph Maliakal, Emad E. Mousa and Varna Menon (2014) Giant Prostatic Hyperplasia Fourth largest prostate reported in medical literature. Sultan Qaboos University Med J 14-2:253-256

Figures

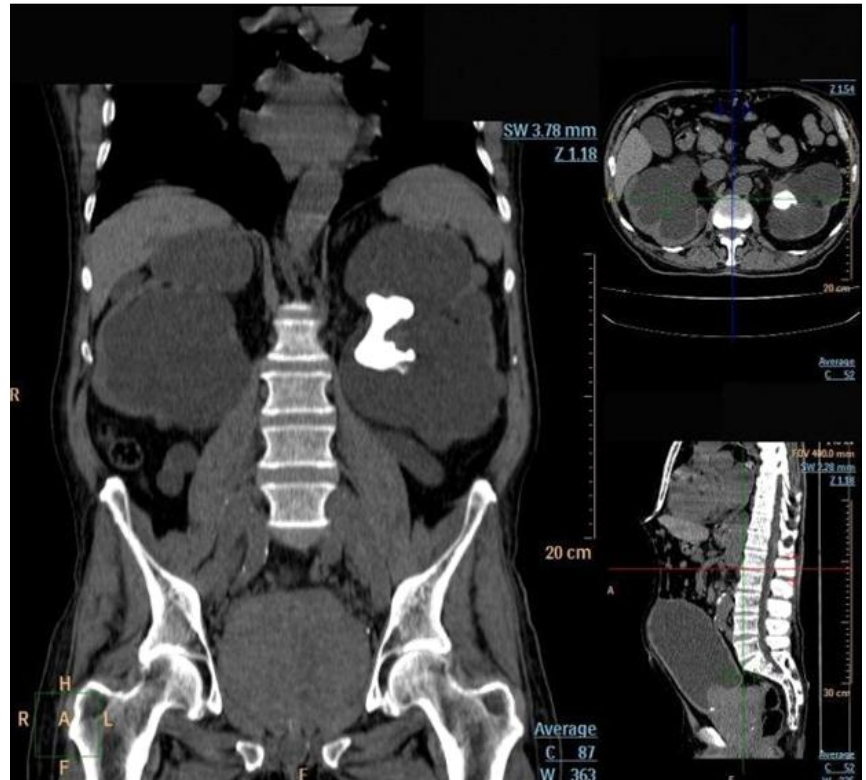

Figure 1: Coronal CT view: Note the high grade of hydronephrosis on both kidneys and the big coral like stone on left renal pelvis

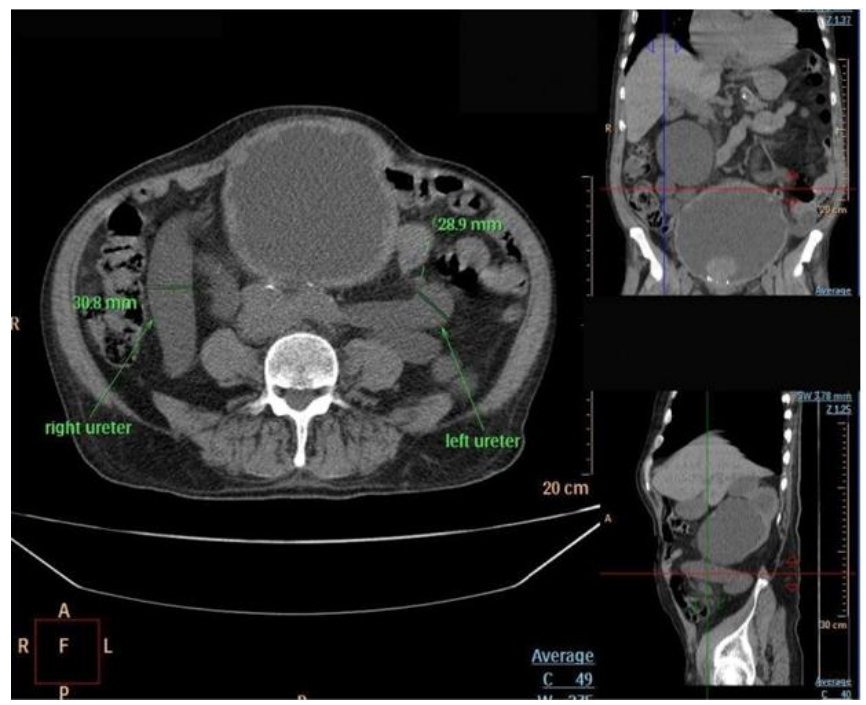

Figure 2: Axial CT view: Note the dilatated and tortuous ureters on both sides

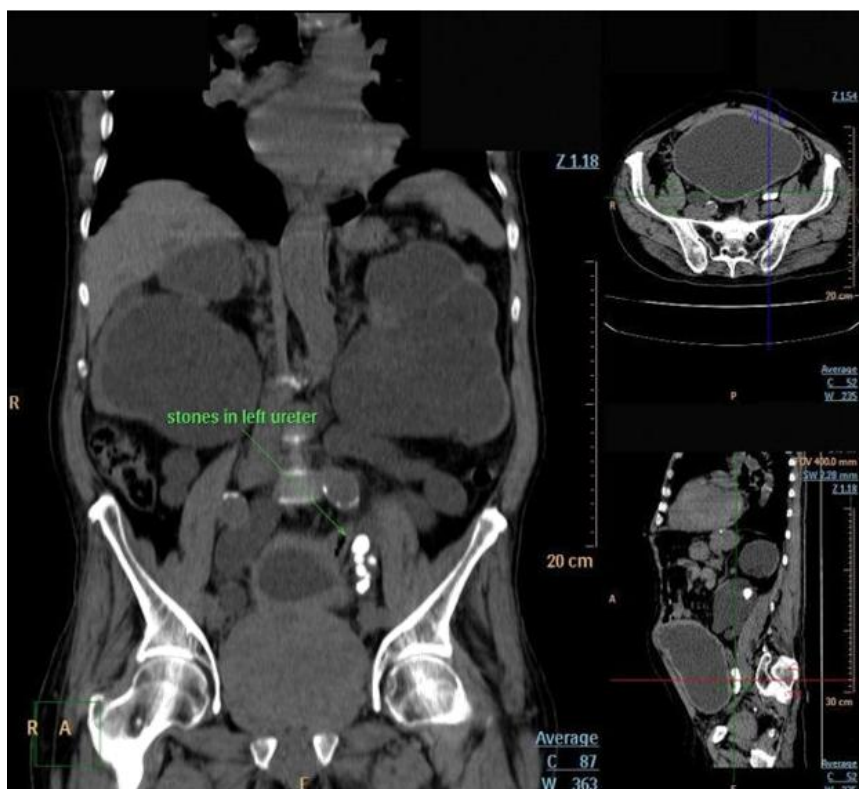

Figure 3: Coronal CT view: Note the stones on the distal third of left ureter

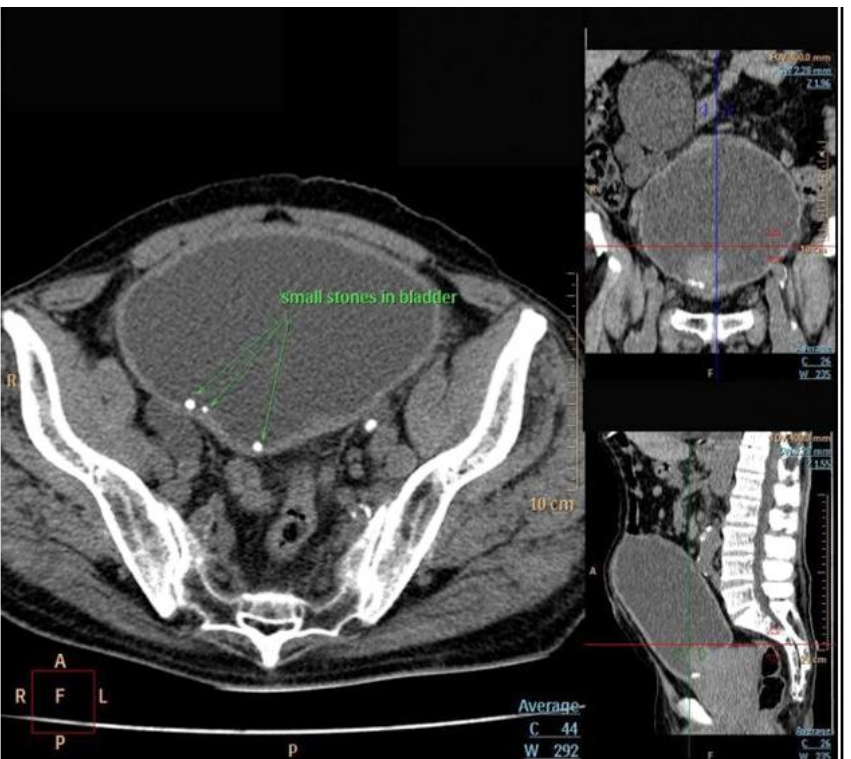

Figure 4: Axial CT view: Note the small stones in urinary bladder

Volume 5 Issue 7, July 2016 www.ijsr.net 
International Journal of Science and Research (IJSR)

ISSN (Online): 2319-7064

Index Copernicus Value (2013): 6.14 | Impact Factor (2015): 6.391

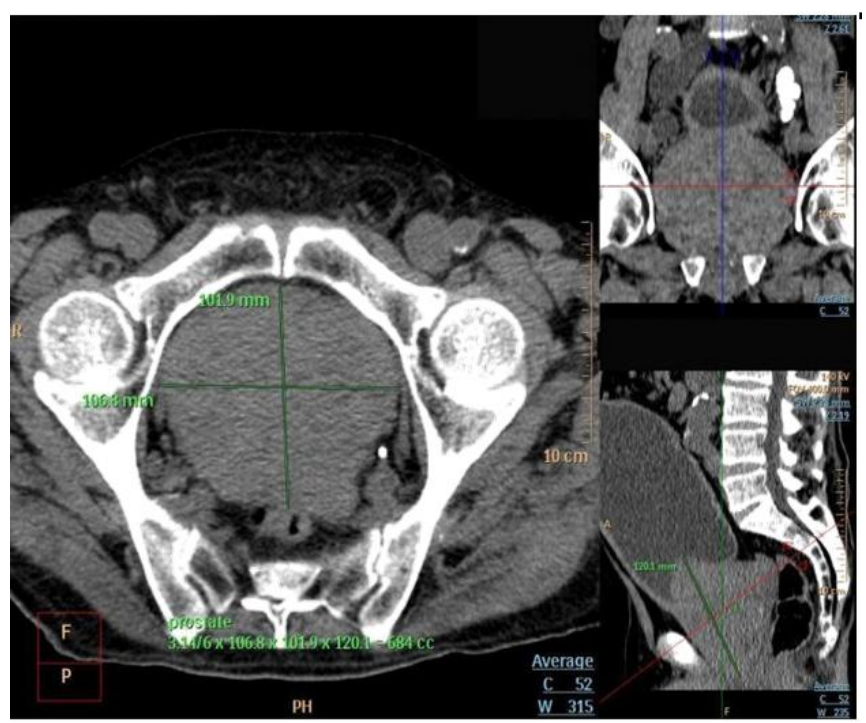

Figure 5: Axial CT view: Note the enormous dimensions of the prostate

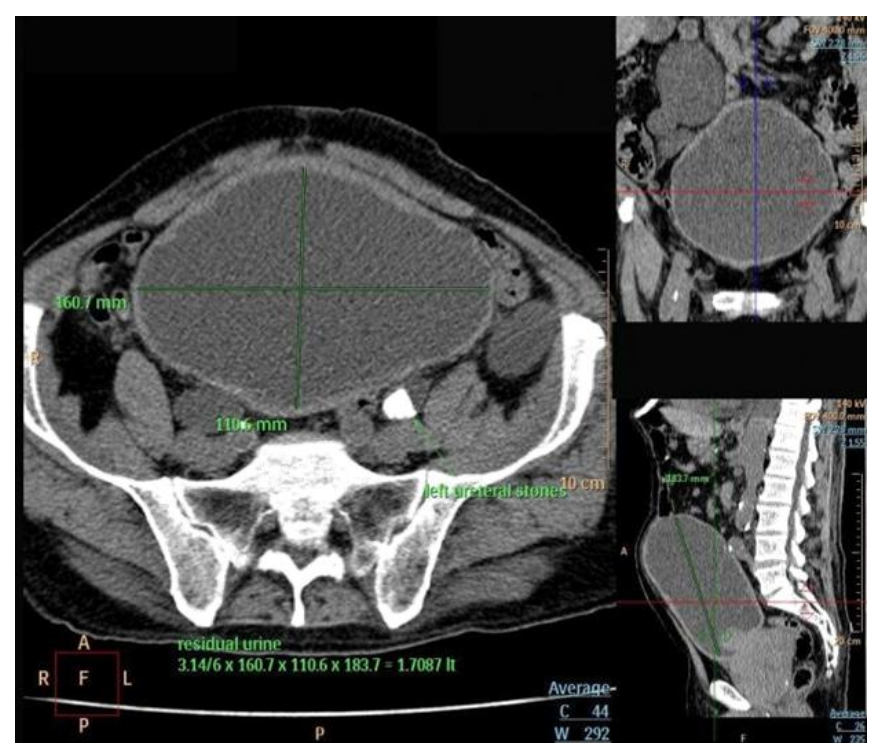

Figure 6: Axial CT view: Note the giant volume of residual urine

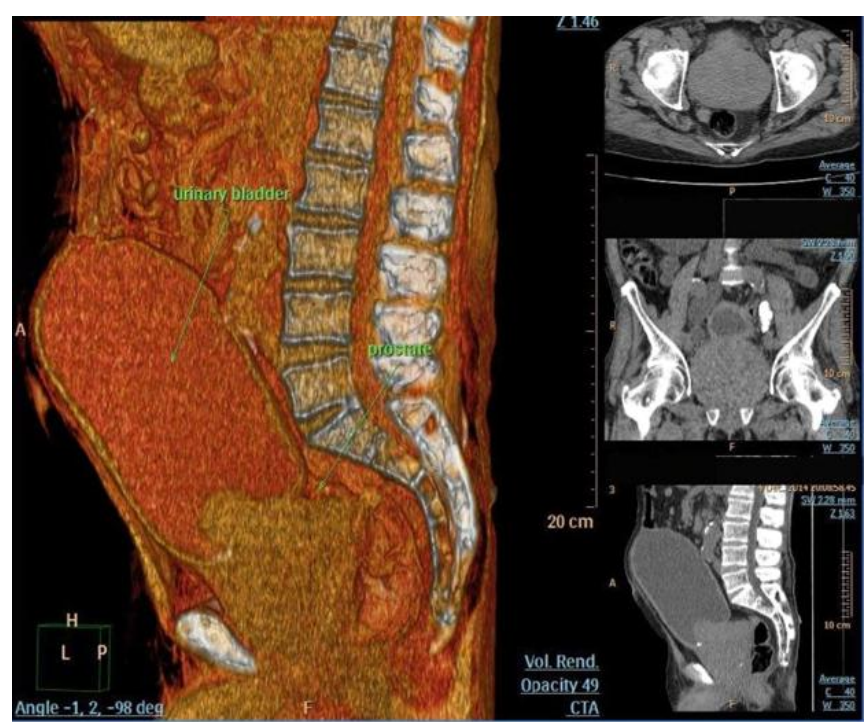

Figure 7: Volume rendering reconstruction view: Note the the prostate volume and residual urine volume

Volume 5 Issue 7, July 2016 www.ijsr.net 